\title{
Link between immunoexpression of hMLH1 and hMSH2 proteins and clinical-epidemiological aspects of actinic cheilitis*
}

\author{
Dmitry José de Santana Sarmento ${ }^{1}$ \\ Márcia Cristina da Costa Miguel $^{3}$
}

\author{
Gustavo Pina Godoy ${ }^{2}$ \\ Éricka Janine Dantas da Silveira ${ }^{3}$
}

DOI: http://dx.doi.org/10.1590/abd1806-4841.20164800

\begin{abstract}
BACKGROUND: The studies found in the literature associate the immunoexpression of hMLH1 and hMSH2 proteins with histologic aspects, but do not correlate it with clinical and epidemiological data.

ОвјестіvE: To evaluate the immunoexpression of hMLH1 and hMSH2 in actinic cheilitis, correlating it with clinical characteristics.

METHODS: We analyzed 40 cases. Histological and immunohistochemical analyses were performed. The following clinical variables were evaluated: gender, age range, ethnicity, clinical aspect and occupational sunlight exposure. Statistical evaluation included the Student t-test, while the significance level was set at $5 \%$.

RESULTS: Greater immunoexpression of hMLH1 and hMSH2 was observed in females, individuals aged over 40, and mixedrace/black patients. Furthermore, the immunoexpression of these proteins was greater in actinic cheilitis with a white-colored appearance and in patients without occupational sunlight exposure. No statistical differences were observed for the variables studied.

CONCLUSION: This study uncovered variations of hMLH1 and hMSH2 protein expression upon evaluation of clinical aspects in actinic cheilitis.
\end{abstract}

Keywords: Cheilitis; Clinical diagnosis; Immunohistochemistry

\section{INTRODUCTION}

Actinic cheilitis (AC) is a potentially malignant lesion affecting mainly the lower lip. It is caused by chronic and excessive exposure of the lips to ultraviolet radiation, especially UVB. It affects primarily white-skinned men, aged 40-60, whose occupational activities involve chronic sun exposure. ${ }^{1,2}$

Exposure to ultraviolet radiation causes disruption of the cell cycle and damage to DNA repair systems. These systems perform physiological functions that play a fundamental role in maintaining normal cell function. The mismatch repair system (MMR) is involved in correcting damage. Human mutS homolog 2 (hMSH2) and human mutL homolog 1 (hMLH1) are genes that are integrated in the MMR system of DNA bases. These genes produce the pro- teins hMSH2 and hMLH1, which are fundamental for the system. The inactivation of one or more MMR genes will not correct the mismatched bases, which may cause the destabilization of microsatellite sequences in both non-coding and coding portions of the genome, resulting in microsatellite instability (MSI).,4

Changes in immunoexpression of the hMLH1 and hMSH2 proteins are frequently detected in potentially malignant lesions as $\mathrm{AC}$ and cancer. In normal tissues, the immunoexpression of the hMSH2 and hMLH1 has also been studied and correlated with the MMR system's normal function. ${ }^{5-8}$

The studies found in the literature associate the immunoexpression of hMLH1 and hMSH2 proteins with histologic aspects, but 
do not correlate it with clinical and epidemiological data. ${ }^{4,5,8}$ Thus, this study aimed to evaluate the immunohistochemical expression of hMLH1 and hMSH2, comparing it with clinical aspects of AC. To our knowledge, this study is the first to associate the immunoexpression of those proteins with clinical parameters, which is important to enhance understanding of these lesions' behaviour in patients with different clinical.

\section{METHODS}

Ethical considerations

The study was approved by the Research Ethics Committee of the Federal University of Rio Grande do Norte (UFRN) (CEP/UFRN-028/2010).

\section{Tissue specimens}

We analyzed 40 blocks of tissue specimens with $\mathrm{AC}$, obtained from the Laboratory of Oral Pathology, Department of Dentistry, UFRN, Natal, Rio Grande do Norte. The diagnosis of AC was confirmed by reviewing patients' histopathological and clinical data. The following inclusion criteria were applied: 1 . AC with a white and/or red clinical appearance; 2 . located on the lower lip. The clinical variables of gender, age, ethnicity, clinical aspect and occupational sunlight exposure, were evaluated. The immunoexpression of hMLH1 and hMSH2 proteins was compared with these variables.

\section{Morphological study}

For histological examination, 5- $\mu \mathrm{m}$-thick sections stained with hematoxylin and eosin were analyzed. To diagnose AC, basophilic changes in the connective tissue were required (basophilic changes are characterized by the replacement of eosinophilic collagen by an amorphous basophilic granular material), not with standing the presence of dysplasia. We adopted the World Health Organization (WHO) criteria for grading epithelial dysplasia. Two oral pathologists, who were unaware of the demographic, histological and clinical characteristics of the sample, analyzed the samples.

\section{Immunohistochemistry}

For immunohistochemical analysis, $3-\mu \mathrm{m}$-thick sections were mounted on organosilane-coated slides (3-aminopropyltriethoxysilane; Sigma Chemical Co., St. Louis, MO, USA). Primary mouse monoclonal antibodies against hMLH1 and hMSH2 were used. The specifications of anti-hMLH1 (clone: G168-15, Pharmingen - San Diego, CA, USA) were 1:200 dilution, Tris-EDTA pH 9.0 for antigen retrieval, and 18 hours (Overnight) for incubation. The specifications of anti-hMSH2 (clone: G219-1129, Pharmingen - San Diego, CA, USA) were 1:200 dilution, no antigen retrieval, and 18 hours (Overnight) for incubation. After antigen retrieval, endogenous peroxidase was blocked with a 1:1 solution of methanol and $3 \%$ hydrogen peroxide. Antibodies were detected by immunoperoxidase staining, using a dextran polymer-based signal enhancement technique (ADVANCE ${ }^{\mathrm{TM}}$, Dako, Carpinteria, CA, USA). The reaction was developed with diaminobenzidine as chromogen. The sections were counterstained with Mayer's hematoxylin and mounted in Permount ${ }^{\circledR}$ (Fisher Scientific, Fair Lawn, NJ, USA). Negative con- trols consisted of the replacement of the primary antibodies with bovine serum albumin, while samples of normal oral mucosa and colon carcinoma specimen with known positive reactivity were included as positive controls.

\section{Quantification of immunostained cells}

According to Caldeira et al. ${ }^{5}$, evaluation of the whole epithelium is more relevant than separate analysis of each epithelial layer. ${ }^{5}$ Only epithelial cells that exhibited brown nuclear immunoreactivity were considered positive.

The specimens were examined under a light microscope (Olympus CH30, Olympus Co., Tokyo, Japan) by two properly calibrated oral pathologists, in a blind study. Initially, the slide area with the largest number of immunostained cells was identified at 100x magnification. Next, consecutive fields of each case were photographed at 400x magnification using the Infinity 1-3C camera (Lumenera Co., Ottawa, Canada), coupled to a light microscope (Nikon Eclipse E200MV, Nikon, Tokyo, Japan). The images were captured using the Lumenera Infinity Analyze software, version 5.0.3. One thousand cells were counted (positive and negative cells) using the ImageJ program (ImageJ for Mac OS X, version 1.44, 64-bit Java: Wayne Rasband, National Institute of Health, USA). Using this software does not affect interpretation, since the software is only used to mark the cells counted, not to change the processed image.

\section{Data analysis}

The data were analyzed using the SPSS 18.0 software (SPSS, Inc., Chicago, IL, USA). A normal distribution was observed, while the Student t-test was used to compare the mean immunoexpression of hMLH1 and hMSH2 between clinical variables. A significance level of $5 \%$ was adopted.

\section{RESULTS}

We observed that patients were represented by males $(3: 1)$ with a mean age of $53.5 \pm 17.04$ years. Sixteen $(40.0 \%)$ cases showed no dysplasia, though mild dysplasia was observed in $10(25.0 \%)$, moderate dysplasia in 11 (27.5\%) and severe dysplasia in $3(7.5 \%)$. The immunoexpression of these proteins was higher in women under 40 and among black and mixed-race individuals, but without significant differences. AC with a white-colored appearance and patients without occupational sunlight exposure, also presented greater immunoexpression of these proteins; no statistical differences were observed for the variables studied. There is a tendency of the expression these proteins in actinic cheilitis not related to solar factor (Table 1). The immunoexpression images are shown in figure 1.

\section{DISCUSSION}

$\mathrm{AC}$ is a potentially malignant lesion on the lips with a trend for malignant transformation from 10 to $30 \% .{ }^{1,5,9}$ It is more prevalent among men, caucasians, with a male-to-female ratio of 2-4:1. The peak of prevalence is observed in patients aged over $40 .^{1,9-11} \mathrm{All}$ the aforementioned characteristics were noted in this sample. Most AC patients had professional activities involving sun exposure, confirming $\mathrm{AC}^{\prime}$ s association with ultraviolet radiation as the main risk factor for this lesion. ${ }^{12,13}$ 
TABLE 1: hMLH1 and hMSH2 immunoexpression in epidemiological and clinical characteristics of actinic cheilits

\begin{tabular}{|c|c|c|c|c|c|c|}
\hline \multirow[t]{3}{*}{ VARIABLE } & & \multirow[t]{3}{*}{ n } & \multicolumn{4}{|c|}{ IMMUNOEXPRESSION } \\
\hline & & & \multicolumn{2}{|l|}{ hMLH1 } & \multicolumn{2}{|l|}{ hMSH2 } \\
\hline & & & mean+SD ${ }^{(a)}$ & $\mathbf{p}^{(\mathbf{b})}$ & mean+SD ${ }^{(a)}$ & $\mathbf{p}^{(\mathbf{b})}$ \\
\hline \multirow[t]{2}{*}{ Gender } & Male & 30 & $640,93+163,13$ & 0.338 & $714,47+187,97$ & 0.658 \\
\hline & Female & 10 & $698,40+159,41$ & & $744,10+161,68$ & \\
\hline \multirow[t]{2}{*}{ Age range } & $\geq 40$ years & 32 & $655,53+171,09$ & 0.986 & $728,16+177,48$ & 0.665 \\
\hline & $<40$ years & 8 & $654,38+129,67$ & & $696,75+201,33$ & \\
\hline \multirow[t]{2}{*}{ Ethnicity* } & White & 26 & $659,73+150,14$ & 0.459 & $711,69+190,78$ & 0.371 \\
\hline & Mixed-race/black & 9 & $705,00+173,88$ & & $775,67+153,49$ & \\
\hline \multirow[t]{2}{*}{ Clinical aspect* } & White lesion & 20 & $706,75+139,74$ & 0.166 & $753,00+163,34$ & 0.615 \\
\hline & Red lesion & 14 & $634,07+157,32$ & & $720,57+209,11$ & \\
\hline \multirow[t]{2}{*}{ Occupational sunlight exposure* } & Yes & 24 & $663,88+142,09$ & 0.372 & $702,58+202,60$ & 0.524 \\
\hline & No & 11 & $712,36+159,97$ & & $746,64+149,09$ & \\
\hline
\end{tabular}

Legends: SD - standard deviation; ${ }^{*}$ The variables have missing data; (a): The data presented comprise the number of positive cells per 1,000 lesional cells; (b): T-student test.

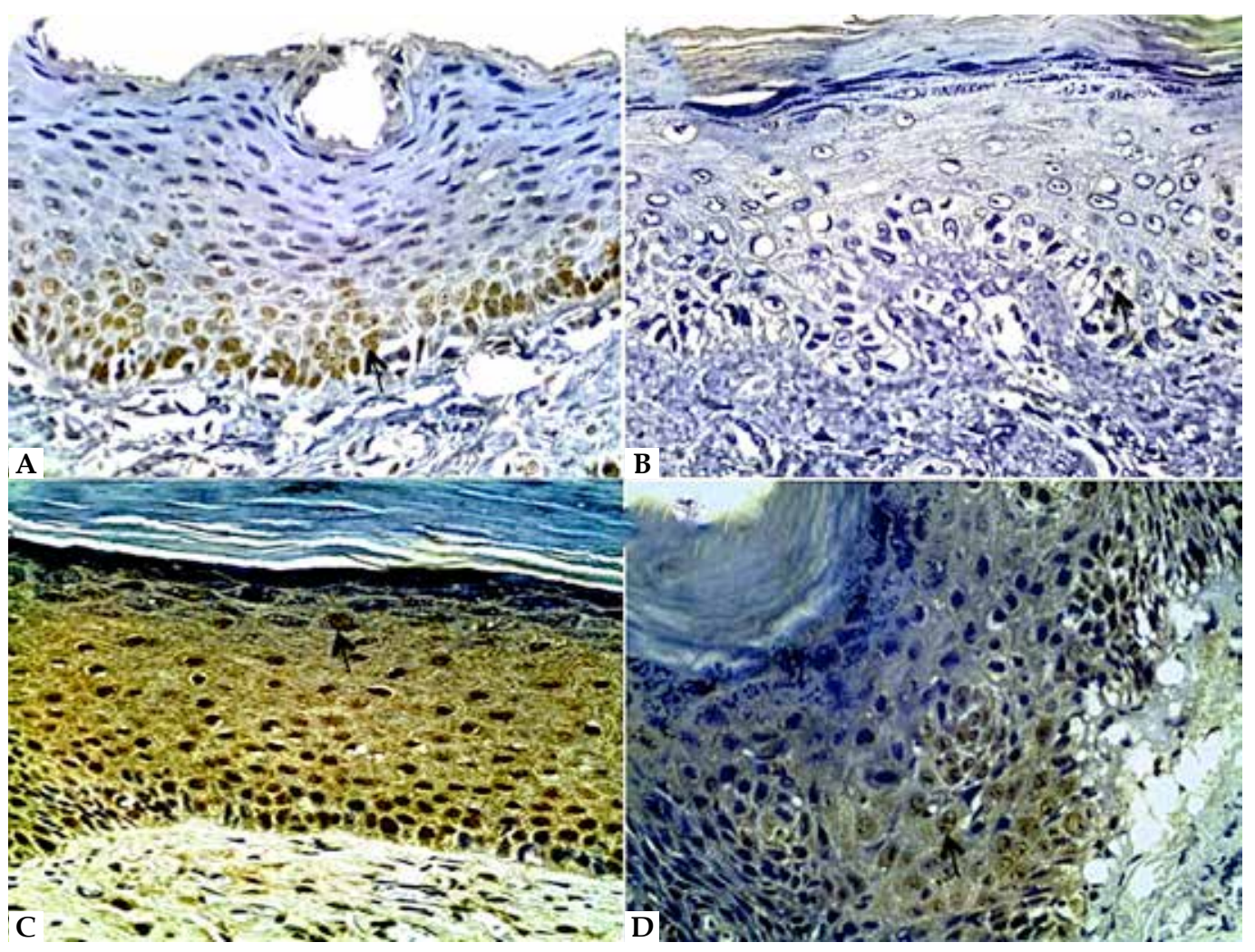

Figure 1:

Immunoexpression of hMLH1 and hMSH2 in actinic cheilitis (AC). (a) Immunostaining of hMLH1 in AC with mild dysplasia (arrow). Patient presented white lesion in lower lip; (b) Immunoexpression of hMLH1 protein in AC with moderate dysplasia (arrow). Patient presented white and red lesion in lower lip; (c) Immunoexpression of hMSH2 protein in AC without dysplasia (arrow). Patient presented white lesion in lower lip; (d) Immunostaining of hMSH2 protein in AC with moderate dysplasia (arrow). Patient presented white lesion in lower lip. (ADVANCE, HRP-400x)
Ultraviolet radiation can cause direct and indirect damage to DNA through oxidative stress, promoting mutations in key genes linked to cell proliferation, DNA repair and/or death cells. ${ }^{4,14,15}$ These changes can be corrected by the MMR system. MMR proteins (hMLH1 and hMSH2) are important for maintaining gene stability, participating in cell cycle arrest, correcting errors in replication, whilst stimulating programmed cell death in cases of irreversible erros. ${ }^{16}$ Some studies have evaluated the immunoexpression of these proteins in the degrees of dysplasia that AC may present, as well as in cancer, but no study has correlated the immunoexpression 
of these proteins with epidemiological and clinical aspects in AC. 5,6,8,17-19 This study is the first in the literature to analyze differences in expression of hMLH1 and hMSH2 proteins, correlating it with epidemiological and clinical characteristics of AC.

Regarding the immunoexpression of hMLH1 and hMSH2 proteins and its association with clinical parameters, we found that females showed greater immunoexpression of both proteins evaluated. We believe that this is due to women's use of lipstick, which prevents damage caused by ultraviolet radiation. The protective action of lipstick has been reported by other studies.,20

The immunoexpression of hMLH1 was identical across the various age groups. For the hMSH2 protein, people aged over 40 presented higher levels of immunoexpression. Fernandes et $a l .{ }^{18}$ evaluated oral mucosa while Caldeira et al. ${ }^{5}$ analyzed oral leukoplakia, uncovering no association between sex/age and the expression of these proteins. Additionally, the authors reported that lesion sites do not influence immunoexpression. Helal et al. ${ }^{21}$ examined oral squamous cell carcinoma and oral dysplastic lesions, finding no significant differences in the immunoexpression of hMSH2 for the variables of sex and age.

Regarding ethnicity, we observed in our study a higher immunoexpression of the proteins in the mixed-race/black group. Skin type is an important factor in AC; patients with white skin have a higher likelihood of developing AC. The protective effects of melanin in natural skin against the carcinogenic action of ultraviolet radiation can explain the higher immunoexpression of hMLH1 and hMSH2 in black and mixed-race individuals. ${ }^{1,22}$

Immunohistochemical staining of hMLH1 and hMSH2 proteins is negative when the genes that encode them are mutated. Therefore, a reduction in immunoexpression of these proteins is regarded as related to the development of premalignant and malignant lesions..$^{5-8,17,18}$ This explains why the profiles of women aged over 40 and of mixed-race and black individuals involve greater immunoexpression of hMLH1 and hMSH2 proteins, confirming that these groups undergo fewer mutations in these genes and experience a lower risk of malignant transformation.

In assessing the clinical aspect, white lesions showed greater immunoexpression for proteins compared with red lesions. Given the results, we believe that red lesions exhibit more aggressive behavior than white lesions. In the literature, the relationship between red lesions and more severe dysplasia or squamous cell carcinoma is well recognized. . $^{1,10,20,23,24}$

Moreover, we found that people who performed professional activities without sun exposure, possessed greater immunoexpression of both hMLH1 and hMHS2 proteins than workers exposed to sunlight. This result confirms the damage in the MMR system caused by ultraviolet exposure. ${ }^{3,4,15}$ The promotion or activation of hMSH2 expression may be induced by the increased DNA damage due to sun exposure. Further, the expression decreases with the severity of the lesion, from precancerous lesions to scamous cell carcinoma. ${ }^{25}$

This study aimed to assess whether the immunoexpression of hMLH1 and hMSH2 proteins bore a relationship with clinical variables in AC. Despite the differences noted regarding the immunoexpression of these proteins in the variables, no significant statistical differences were observed. Fernandes et al. ${ }^{18}$ reported that these results may reflect the primitive function and basic MMR system, as conserved throughout evolution and unchanged in demographic changes.

This paper presents data suggesting that clinical characteristics are involved in changing the immunoexpression of these proteins. AC is a lesion with malignant potential and entailing progression to squamous cell carcinoma of the lips. The hMLH1 and hMSH2 proteins are actively involved in the carcinogenesis process of this lesion, since immunoexpression decreases as the lesion becomes more severe. ${ }^{5-8,17,18}$ It is normal to uncover a high expression of these proteins in normal patients. ${ }^{18}$ Lower immunoexpression of hMLH1 and hMSH2 was noted in white males aged under 40. AC with a red appearance and patients with occupational sunlight exposure also presented lower immunoexpression of these proteins. The decreased immunoexpression of the proteins studied is directly related to the risk of cancer. ${ }^{7,19,21}$ Hence, the aforementioned group can be characterized as a higher-risk group for progression of $\mathrm{AC}$ to squamous cell carcinoma of the lips.

For dermatologists, this study enhances understanding of the pathogenesis of $\mathrm{AC}$, as well as the behavior of these lesions in patients with clinical differences. The survey also identified the highest-risk group for developing premalignant and malignant lesions, whilst outlining the lower-risk group, both related to the immunosuppression of hMLH1 and hMSH2 proteins, which is clearly linked to cancer progression.

\section{CONCLUSION}

In summary, the results of this study showed variations in the immunoexpression of hMLH1 and hMSH2 proteins, as reflected in the evaluation of epidemiological and clinical AC characteristics. Despite the differences observed, further studies are necessary to confirm these trends.] 


\section{REFERENCES}

1. Piñera-Marques K, Lorenço SV, Silva LF, Sotto MN, Carneiro PC. Actinic lesions in fishermen's lower lip: clinical, cytopathological and histopathologic analysis. Clinics (Sao Paulo). 2010;65:363-7.

2. Junqueira JL, Bönecker M, Furuse C, Morais Pde C, Flório FM, Cury PR, et al. Actinic cheilitis among agricultural workers in Campinas, Brazil. Community Dent Health. 2011;28:60-3.

3. Rodust PM, Stockfleth E, Ulrich C, Leverkus M, Eberle J. UV-induced squamous cell carcinoma--a role for antiapoptotic signalling pathways. $\mathrm{Br} \mathrm{J}$ Dermatol. 2009;161:107-15.

4. Ikehata H, Ono T. The mechanisms of UV mutagenesis. J Radiat Res. 2011;52:11525.

5. Caldeira PC, Abreu MH, Batista AC, do Carmo MA. hMLH1 immunoexpression is related to the degree of epithelial dysplasia in oral leukoplakia. J Oral Pathol Med. 2011;40:153-9.

6. González-Ramírez I, Ramírez-Amador V, Irigoyen-Camacho ME, Sánchez-Pérez Y, Anaya-Saavedra G, Granados-García M, et al. hMLH1 promoter methylation is an early event in oral cancer. Oral Oncol. 2011;47:22-6.

7. Souza LR, Fonseca-Silva T, Pereira CS, Santos EP, Lima LC, Carvalho HA, et al. Immunohistochemical analysis of p53, APE1, hMSH2 and ERCC1 proteins in actinic cheilitis and lip squamous cell carcinoma. Histopathology. 2011;58:35260.

8. Fernandes AM, Ramos-Jorge ML, Cardoso SV, Loyola AM, Mesquita RA, Aguiar MC. Immunoexpression of hMSH2 and hMLH1 in oral squamous cell carcinoma and its relationship to histological grades of malignancy. J Oral Pathol Med. 2008;37:543-8.

9. Menta Simonsen Nico M, Rivitti EA, Lourenço SV. Actinic cheilitis: histologic study of the entire vermilion and comparison with previous biopsy. J Cutan Pathol. 2007;34:309-14

10. Cavalcante AS1, Anbinder AL, Carvalho YR. Actinic cheilitis: clinical and histological features. J Oral Maxillofac Surg. 2008;66:498-503.

11. Ntomouchtsis A, Karakinaris G, Poulolpoulos A, Kechagias N, Kittikidou K, Tsompanidou C, et al. Benign lip lesions. A 10-year retrospective study. Oral Maxillofac Surg. 2010;14:115-8.

12. Bentley JM, Barankin B, Lauzon GJ. Paying more than lip service to lip lesions. Can Fam Physician. 2003;49:1111-6.

13. de Freitas Mda C, Ramalho LM, Xavier FC, Moreira AL, Reis SR. p53 and MDM2 protein expression in actinic cheilitis. J Appl Oral Sci. 2008;16:414-9.

14. de Gruijl FR, Voskamp P.. Photocarcinogenesis-DNA damage and gene mutations. Cancer Treat Res. 2009;146:101-8.

15. Narayanan DL, Saladi RN, Fox JL. Ultraviolet radiation and skin cancer. Int J Dermatol. 2010;49:978-86.

16. Jun SH, Kim TG, Ban C. DNA mismatch repair system. Classical and fresh roles. FEBS J. 2006;273:1609-19.

17. Pontes HAR, Aguiar MCF, Mesquita RA, Santos EP, Lima LC, Carvalho HA, et al. Imunodetection of repair protein $\mathrm{hMSH} 2$ in actinic cheilitis and normal labial mucosa. Rev Bras Cancerol 2005;51:23-30.

18. Fernandes AM, De Souza VR, Springer CR, Cardoso SV, Loyola AM, Mesquita $\mathrm{RA}$, et al. Tobacco and inflammation effects in immunoexpression of hMSH2 and hMLH1 in epithelium of oral mucosa. Anticancer Res. 2007;27:2433-7.

19. Czerninski R, Krichevsky S, Ashhab Y, Gazit D, Patel V, Ben-Yehuda D. Promoter hypermethylation of mismatch repair genes, hMLH1 and hMSH2 in oral squamous cell carcinoma. Oral Dis. 2009;15:206-13.

20. de Souza Lucena EE, Costa DC, da Silveira EJ, Lima KC. Prevalence and factors associated to actinic cheilitis in beach workers. Oral Dis. 2012;18:575-9.

21. Helal Tel A, Fadel MT, El-Thobbani AK, EI-Sarhi AM. Immunoexpression of p53 and hMSH2 in oral squamous cell carcinoma and oral dysplastic lesions in Yemen: relationship to oral risk habits and prognostic factors. Oral Oncol. 2012;48:120-4.
22. Vieira RA, Minicucci EM, Marques ME, Marques SA. Actinic cheilitis and squamous cell carcinoma of the lip: clinical, histopathological and immunogenetic aspects. An Bras Dermatol. 2012;87:105-14.

23. Markopoulos A, Albanidou-Farmaki E, Kayavis I. Actinic cheilitis: clinical and pathologic characteristics in 65 cases. Oral Dis. 2004;10:212-6.

24. Jadotte YT, Schwartz RA. Solar cheilosis: an ominous precursor: part I. Diagnostic insights. J Am Acad Dermatol. 2012;66:173-84

25. Liang SB, Furihata M, Takeuchi T, Sonobe H, Ohtsuki Y. Reduced human mismatch repair protein expression in the development of precancerous skin lesions to squamous cell carcinoma. Virchows Arch. 2001;439:622-7.

\author{
MAILING ADDRESS: \\ Dmitry José de Santana Sarmento \\ Avenida Coronel Pedro Targino, $s / n$ \\ Centro \\ 58233-000 - Araruna - PB \\ Brazil \\ E-mail:dmitry_sarmento@hotmail.com
}

How to cite this article: Sarmento DJS, Godoy GP, Miguel MCC, Silveira EJD. Link between immunoexpression of hMLH1 and hMSH2 proteins and clinical-epidemiological aspects of actinic cheilitis. An Bras Dermatol. 2016;91(4):463-7. 